\title{
ANALISIS FUNGSI PRODUKSI USAHA TERNAK SAPI DI KECAMATAN TOMPASO BARAT KABUPATEN MINAHASA
}

\author{
Aprillia M. Thamrin, Femi H. Elly*, Nansi Santa, Merry A.V. Manese
}

Fakultas Peternakan Universitas Sam Ratulangi Manado, 95115

\begin{abstract}
ABSTRAK
Ternak sapi potong diusahakan oleh petani peternak di Kecamatan Tompaso Barat dengan cara tradisional dan merupakan usaha sambilan. Pemerintah dalam hal ini juga mendorong petani peternak dalam meningkatkan

produksi.Permasalahannya apakah faktor produksi yang digunakan berpengaruh terhadap produksi ternak sapi potong.Penelitian ini bertujuanuntuk mengetahui faktorfaktor yang mempengaruhi produksi ternak sapi potong.Data yang dikumpulkan adalah data primer dan data sekunder.Pengambilan sampel menggunakan metodeCluster Random Sampling.Analisis data yang digunakan adalah regresi berganda dengan pendekatan ekonometrika dan menggunakan software program SAS 9,4 . Hasil penelitian menunjukkan bahwa umur responden berkisar antara 30-65 tahun sehingga dikategorikan umur produktif. Berdasarkan hasil penelitian dapat disimpulkan bahwa secara bersama-sama faktor produksilahan, tenaga kerja dan pakan berpengaruh nyata terhadap produksi ternak sapi potong. Faktor produksilahan dan pakan yang berpengaruh nyata terhadap produksi sapi potong.
\end{abstract}

*Korespondensi(correspondingauthor) E-mail: femihelly@unsrat.ac.id
Kata Kunci : Lahan, tenaga kerja, pakan, ternak sapi

\begin{tabular}{llr}
\multicolumn{3}{c}{ ABSTRACT } \\
PRODUCTION & \multicolumn{2}{c}{ FUNCTION } \\
ANALYSIS & OF & CATTLE \\
FARMING IN & WEST & TOMPASO \\
DISTRICT & REGENCY & OF \\
MINAHASA.Farmers in & West
\end{tabular}

Tompaso district cultivatedBeef cattle traditionally and not as main farming. The government in this case also encourages farmers to increase production. The problem is whether the production factor used affects the production of beef cattle. The research aims to determine the factors affecting cattle production. The data collected is primary data and secondary data. Sampling uses the Cluster Random Sampling method. The analysis of the data used is multiple regression with econometrics approaches and software using SAS program 9.4. The results showed that the respondents ' lifespan ranged from 30-65 years to categorized productive age. Based on the results of the study can be concluded that together the factors of land production, labor and feed are real effect on the production of beef cattle. Land production and feed factors that have real effect on the production of beef cattle.

Keywords: Land, labor, feed, beef cattle 


\section{PENDAHULUAN}

Peternakan sebagai salah satu bagian dari sektor pertanian, berperan penting menunjang kebutuhan terhadap pangan dan pembangunan sumberdaya manusia yang lebih berkualitas.Peran subsektorpeternakan dalam pembangunan berdampak positif terhadap perekonomian suatu wilayah.Program pembangunan peternakan sapi potong selalu dikaitkan dengan reorientasi kebijakan pertanian (Ikbal, 2015).Meningkatnya jumlah penduduk dan kesadaran masyarakat terhadap pentingnya gizi sangat menunjang terhadap peningkatan konsumsi pangan.Sektor peternakan sapi potong mempunyai peranan yang sangat penting dalam pembangunan nasional khususnya ketersediaan pangan nasional dalam bentuk daging sebagai salah satu produk peternakan (Sukmayadi et al.,2016).

Salah satu sektor pertanian yang memiliki potensi besar untuk dapat dikembangkan adalah peternakan sapi potong (Priyanto, 2011).Ternak sapi potong diusahakan oleh petani peternak di Kecamatan Tompaso dengan cara tradisional dan merupakan usaha sambilan. Berbagai upaya telah dilakukan petani peternak dalam rangka meningkatkan produksi ternak sapi.Pemerintah dalam hal ini juga mendorong petani peternak dalam meningkatkan produksi diantaranya adanya bantuan modal.Peningkatan produksi sapi potong perlu mendapat perhatian serius karena berkaitan dengan konsumsi produk peternakan yang cenderung meningkat.Konsumsi hasil ternak berupa daging segar di Indonesia tahun 2011 sebesar 5,110 $\mathrm{kg} / \mathrm{kapita} /$ tahun atau mengalami kenaikan sebesar 5,38 persen bila dibandingkan dengan tahun 2010 sebesar $\quad 4,859 \quad \mathrm{~kg} / \mathrm{kapita} / \mathrm{tahun}$. Indikasinya bahwa kebutuhan daging cenderung terus meningkat seiring peningkatan pertumbuhan jumlah penduduk.

Tompaso Barat sebagai salah satu kecamatan di Kabupaten Minahasa merupakan wilayah sentra pengembangan ternak sapi potong.Hal ini disebabkan karena Kecamatan Tompaso Barat adalah salah satu wilayah yang memiliki sumberdaya ternak sapi potong terbanyak di Kabupaten Minahasa.Kecamatan ini menjadi target serta tujuan dalam pengembangan usaha ternak sapi potong yang ditunjang dengan potensi pertanian tanaman pangan. 
Permasalahannya apakah faktor produksi yang digunakan berpengaruh terhadap produksi ternak sapi potong.Penelitian ini bertujuanuntuk mengetahui faktor-faktor yang mempengaruhi produksi ternak sapi di Kecamatan Tompaso Barat, Kabupaten Minahasa.

\section{METODE PENELITIAN}

Penelitian ini dilakukan di Keacamatan Tompaso Barat Kabupaten Minahasa.Pengambilan data dilaksanakan pada bulan Oktober sampai dengan bulan November 2018.Metode penelitian ini yang digunakan adalah metode survey.Pengumpulan data menggunakan teknik wawancara pada masyarakat petani peternak dengan menggunakan kuesioner yang telah disiapkan.Jenis data yang dikumpulkan dari sumber data primer dan data sekunder.Data primer diperoleh dari wawancara langsung dengan responden.Sedangkan data sekunder diperoleh dari instansiinstansi lain yang terkait dengan penelitian ini.Penentuan sampel lokasi dan responden dilakukan dengan menggunakan metode Cluster Random Sampling. Menurut Azwar (2010), metode pengambilan sampel dengan cara klaster (pengambilan sampel secara acak berkelompok)adalah pengambilan dengan melakukan randominasi terhadap kelompok, bukan terhadap subjek secara individual. Variabel yang diukur dalam penelitian ini adalah produksi sapi potong, lahan, tenaga kerja dan pakan.Produksi sapi potong adalah jumlah ternak sapi potong yang dimiliki oleh responden (diukur dalam ST).Luas Lahan adalah keseluruhan lahan yang dimanfaatkan pengembangan tanaman jagung dan rumput sebagai sumber pakan ternak sapi potong (diukur dalam Ha).Tenaga kerja adalah curahan tenaga petani peternak dalam mengelola usaha ternak sapi potong (diukur dalam HOK/Tahun).Pakan adalah jumlah pakan rumput dan limbah jagung yang diberikan kepada ternak sapi potong (diukur dalam Kg/Tahun). Analisis yang digunakan untuk menjawab tujuan penelitian adalah analisis fungsi produksi regresi bergandadengan pendekatan ekonometrika dan menggunakan software program SAS 9,4 .

\section{HASIL DAN PEMBAHASAN}

Keberhasilan usaha peternakan sapi potong tergantung pada 
karakteristik petani peternak. Tingkat pendidikan ini berdampak Karakteristik petani peternak terhadap cepat lambatnya petani diantaranya umur, tingkat pendidikan peternak dalam mengadopsi dan pengalaman dalam berusaha teknologi.Rendahnya tingkat peternakan sapi potong.Hasil penelitian menunjukkan bahwa umur responden berkisar antara 30-65 tahun sehingga dikategorikan umur produktif.Menururt beberapa peneliti bahwa semakin muda seseorang yang dikategorikan dalam usia produktif lebih rensponsif terhadap penerimaan inovasi melalui introduksi teknologi dibandingkan dengan orang yang telah lanjut.Menurut Lubis et al. (2014) usia produktif ditandai dengan cukup terampil dalam mengerjakan sesuatu pekerjaan, dan lebih efektif dalam mengelola usaha ternak sapi potong. Pertimbangan usiatersebut memberi pengaruh terhadap kemampuan petani peternakdalam adopsi teknologi sehingga usaha peternakan sapi potong dapat berkembang ke arah yang lebih baik.

Pendidikan responden adalah salah satu karakteristik responden yang mempengaruhi keberhasilan usaha peternakan sapi potong. Hasil penelitian menunjukkan bahwa sebagian besar tingkat pendidikan petani peternak sebagai responden adalah SD (46,7\%) dan SMP (23,3\%). pendidikan formal sesuai hasil penelitian berdampak terhadap rendahnya pengetahuan petani peternak dalam mengembangkan usaha peternakan sapi.Program yang dapat dilakukan untuk mendorong peningkatan pengetahuan petani peternak adalah melalui peningkatan frekuensi pendidikan informal berupa penyuluhan dan pelatihan.Pendidikan formal menurut Lubis et al. (2014) sangat berdampak terhadap adopsi teknologi dan perubahan kedepan.Tingkat pendidikan yang semakin tinggi menyebabkan informasi dapat diterima dengan baik.

Petani peternak di wilayah penelitian melakukan proses produksi sapi potong dimulai ketika telah membentuk suatu keluarga atau setelah menikah (kawin).Ternak sapi potong yang dikembangkan merupakan warisan orang tua.Pembagian ternak sapi oleh orang tua tujuannya agar ternak sapi dapat digunakan sebagai tenaga kerja untuk mengolah lahan pertanian dan mengangkut produk pertanian.Petani peternak yang tergabung kelompok 
peternak sapi potong mendapat ternak sapi melalui bantuan pemerintah.Lama usaha berkisar 10-20 tahun untuk 20 responden $(66,7 \%)$ dan 21-30 tahun untuk 10 responden $(33,3 \%)$. Lama usaha juga merupakan salah satu karakteristik yang menunjang keberhasilan usaha peternakan sapi potong. Semakin lama petani peternak melalukan proses produksi peternakan sapi diduga dapat mengatasi masalah yang dihadapinya khususnya masalah teknis peternakan. Tetapi pengalaman petani peternak ini harus ditunjang dengan ilmu pengetahuan yang lebih modern dan berorientasi bisnis.

Data hasil penelitian usaha ternak sapi potong masih merupakan kegiatan yang bersifat multiguna, karena selain dipelihara untuk digemukkan, juga sekaligus berfungsi sebagai tenaga kerja. Ternak sapi potong juga dijadikan tabungan bagi para petani peternak dalam satu proses produksi yang sewaktu-waktu dapat dijual untuk digunakan dalam memenuhi kebutuhan mereka. Produksi ternak sapi potong diperoleh secara maksimal berdampak terhadap peningkatan pendapatan petani peternak.Pengelolaan peternakan sapi potong secara efisienberdampak terhadap efisiensi penggunaan factor produksisehingga

menghasilkan keuntungan maksimum (Walia and Kaur, 2013)Menurut Happyana (2017) bahwa petani peternak harus memahami aspek - aspek teknis dan ekonomis produksi untuk memperoleh produksi maksimal dan keuntungan maksimum.Fenomena ini didukung oleh upaya petani peternak dalam meningkatkan produksi dengan memanfaatkan faktor produksi secara optimal.Faktor produksi yang mempengaruhi produksi ternak sapi potong diantaranya lahan, tenaga kerja dan pakan untuk konsumsi ternak sapi potong. Hasil penelitian (Lubis et al., 2014; Sukmayadi., 2016) memasukkan faktor pakan pada analisis fungsi produksi usaha peternakan sapi potong. Hasil estimasi pengaruh faktor lahan, tenaga kerja dan pakan diringkas dalam Tabel 1. 
Zootec Vol. 39 No. 2 : 266-275 (Juli 2019) pISSN 0852-2626 eISSN 2615 - 8698

Tabel 1.Hasil Estimasi Pengaruh Faktor Produksi Lahan, Tenaga Kerja, Pakan Terhadap Produksi Sapi Potong di Kecamatan Tompaso Barat.

\begin{tabular}{cccc}
\hline Variabel & ParameterEstimasi & Nilait-hit & Pr>(t) \\
\hline Intercept & -0.34 & -0.45 & 0.6600 \\
LHAN & 0.25 & 2.39 & $0.0241^{* *}$ \\
CKUS & 0.16 & 0.48 & $0.6351^{*}$ \\
PKAN & 0.58 & 3.66 & $0.0011^{* *}$ \\
\hline F hitung & 7.38 & & \\
R Square & 46.00 & & \\
\hline
\end{tabular}

Keterangan :

**Signifikan pada $\alpha=0.05$

*Non signifikan pada $\alpha=0.05$

Berdasarkan hasil analisis seperti pada Tabel 1, maka nilai parameter estimasi dapat dinyatakan dalam bentuk persamaan fungsi produksi regresi berganda.Hasil estimasi dapat dilihat pada persamaan (1).

$\mathrm{JSPE}=-0.35+0.25 \mathrm{LHAN}+$

0.16CKUS +0.58 PKAN

Keterangan :

JSPE = Jumlah Sapi Potong (Ekor)

LHAN = Lahan tanaman jagung dan rumput (Ha)
CKUS $=$ Curahan Tenaga Kerja Pria pada Usaha Ternak Sapi Potong (HOK/Tahun)

PKAN = Pakan yang dikonsumsi oleh tenak sapi potong ( $\mathrm{Kg} / \mathrm{Tahun})$

Berdasarkan Tabel 1dan Persamaan (1) terlihat bahwa nilai koefisien intersep sebesar -0.34, artinya tanpa penggunaan faktor produksilahan (LHAN), pakan (PKAN), curahan tenaga kerja pria (CKUS) dan lahan (LHAN) maka produksi sapi menurun sebesar0.34. Nilai koefisien regresi dari variabel 
lahan (LHAN) sebesar 0,25, artinya bila luas lahan ditambah 1 unit maka produksi sapi potong bertambah sebesar 0,25 ST, ceteris paribus. Nilai Koefisien regresi dari variabel curahan tenaga kerja pria (CKUS) sebesar 0.16, artinya bila curahan tenaga kerja pria (CKUS) naik 1 HOK maka produksi sapi potong naik sebesar $0.16 \mathrm{ST}$, ceteris paribus.Nilai koefisien regresi dari variabel pakan (PKAN) sebesar 0.58 , artinya bila pakan ditambahkan 1 $\mathrm{kg}$ maka produksi sapi potong naik sebesar $0.58 \mathrm{ST}$, ceteris paribus.

Hasil analisis Uji-F (Overal Test) berdasarkan Tabel 1 menunjukkan bahwa $\mathrm{p}<0.05$. Hal ini menunjukkan bahwa $\mathrm{F}_{\text {hitung }}>\mathrm{F}_{\text {tabel }}$ pada $\alpha=0.05$. Berdasarkan hasil pengujian bahwa $\quad F_{\text {hitung }}>F_{\text {tabel }}$ sehingga $\quad \mathrm{H}_{0}$ ditolak, artinya variabel bebas berpengaruh terhadap variabel terikat. Hasil ini menunjukkan bahwa secara bersama-sama faktor produksi lahan (LHAN), tenaga kerja (CKUS) dan pakan berpengaruh nyata terhadap produksi sapi potong pada tingkat kepercayaan $95 \%$.

Hasil analisis Uji-t (Parsial Test) berdasarkan Tabel 1 terhadap variabel lahan menunjukkan bahwa $\mathrm{p}<0.05$ artinya $t_{\text {hitung }}>\mathrm{t}_{\text {tabel }}$ pada $\alpha=$ 0.05 . Hasil ini menunjukkan bahwa $\mathrm{H}_{0}$ ditolak artinya variabel bebas berpengaruh nyata terhadap variabel terikat. Indikasinya bahwa variabel lahan (LHAN) berpengaruh nyata terhadap produksi sapi potong (JSPE) atau dengan kata lainsignifikan pada tingkat kepercayaan 95\%, ceteris paribus.

Hasil analisis Uji-t (Parsial Test) berdasarkan Tabel 1 terhadap variabel curahan tenaga kerja pria menunjukkan bahwa $\mathrm{p}>0.05$ artinya $t_{\text {hitung }}<t_{\text {tabel }}$ pada pada $\alpha=0.05$. Hasil ini menunjukkan bahwa $\mathrm{H}_{0}$ diterima artinya variabel bebas berpengaruh tidak nyata terhadap variabel terikat. Indikasinya bahwa variabel curahan tenaga kerja pria (CKUS) berpengaruh tidak nyata terhadap produksi sapi potong (JSPE) atau dengan kata lain non signifikan pada tingkat kepercayaan $95 \%, \quad$ ceteris paribus.Hasil penelitian Indrayani et al. (2012) menunjukkan bahwa satu HOK mampu mengelola 4 sampai 5 ekor ternak. Produksi meningkat dengan meningkatkan jam kerja dalam 
pengelolaan sapi potong (Indrayani et al., 2012) diantaranya curahan waktu untuk penyiapan pakan.

\section{Hasil analisis Uji-t (Parsial} Test) berdasarkan Tabel 1 terhadap variabel pakan menunjukkan bahwa $\mathrm{p}<0.05$ pada $\alpha=0.05$ artinya $\mathrm{t}_{\text {hitung }}>\mathrm{t}_{\text {tabel }}$ pada $\alpha=0.05$. Hasil ini menunjukkan bahwa $\mathrm{H}_{0}$ ditolak artinya variabel bebas berpengaruh nyata terhadap variabel terikat. Indikasinya bahwa variabel pakan (PKAN) berpengaruh nyata terhadap produksi sapi potong (JSPE) atau dengan kata lain signifikan pada tingkat kepercayaan 95\%, ceteris paribus. Astuti et al. (2010), Lubis et al. (2014) dan Sukmayadi et al. (2016) memasukkan variabel pakan dalam analisis produksi sapi potong.Menurut Rahmawaty dan Budianto (2011),perbaikan pakan berkualitas untuk ternak sapi potong memiliki manfaat dalam mempersingkat waktu penggemukan sapi. Pakan perlu ditingkatkan sehingga produksi ternak sapi potong bisa berkembang.Teknologi pakan perlu diintroduksi untuk mengolah limbah tanaman jagung menjadi pakan yang berkualitas.Introduksi hijauan berkualitas sangat dibutuhkan untu meningkatkan produksi dan produksi ternak sapi potong (Elly et al.,2018).

Koefisien determinasi $\left(\mathrm{R}^{2}\right)$ sebesar 0.46, artinya naik turunya produksi sapi potong sebesar $46.00 \%$ dipengaruhi oleh naik turunnya variabel luas lahan (LHAN), tenaga kerja (CKUS), pakan yang dikonsumsi (PKAN), dan pakan (LHAN). Sisanya $54.00 \%$ dipengaruhi oleh variabel lain yang tidak dimasukkan dalam model analisis, diantaranya faktor modal, faktor sosial ekonomi petani dan karakteristik petani.

\section{KESIMPULAN DAN SARAN}

Berdasarkan hasil penelitian dapat disimpulkan bahwa secara bersama-sama faktor produksi lahan, tenaga kerja dan pakan berpengaruh nyata terhadap produksi ternak sapi potong. Tetapi secara parsial hanya faktor produksi lahan dan pakan yang berpengaruh nyata terhadap produksi sapi potong.Saran yang direkomendasikan adalah perlu sosialisasi dan introduksi teknologi pakan dengan memanfaatkan limbah 
pertanian. Perlu penelitian lanjutan berkaitan dengan analisis input yang optimal.

\section{DAFTAR PUSTAKA}

Astuti, M., R. Widiati., dan Y.Y. Suranindyah. 2010. Efisiensi produksi usaha peternakan sapi perah rakyat (studi kasus pada peternak anggota koperasi usaha peternakan dan pemerahan sapi perah). Buletin Peternakan 34(1) : 64-69.

Azwar, S. 2010.Dasar-Dasar Psikometri.Pustaka Pelajar.Yogyakarta

Elly, F.H., A.H.S. Salendu, Ch. L. Kaunang., Indriana., R. Pomolango and Syarifuddin. 2018. Forage introduction to support development of cattle in Sangkub District. International Journal of Environment Agriculture and Biotechnology (IJEAB),3(5):1718-1720.

Happyana, D. 2017. Analisis tingkat keuntungan usaha penggemukan sapi potong rakyat di kabupaten Wonogiri. Jurnal Ilmiah Peternakan Terpadu, 5(2) : 33-39.

Ikbal, M. 2015. Evaluasi kebijakan penertiban ternak di kecamatan Parigi kabupaten Parigi Moutong. E-Jurnal Katalogis. 3(10):167-172.
Indrayani, I., R. Nurmalina dan A. Fariyanti. 2012. Analisis efisiensi teknis usaha penggemukan sapi potong di Kabupaten Agam provinsi Sumatera Barat. Jurnal Peternakan Indonesia, 14(1):286-296.

Lubis, B.A., Rahmanta dan Supriadi. 2014. Analisis produksi peternakan sapi dalam mengembangkan wilayah di kabupaten Deli Serdang. Jurnal Ekonomi, 17(2):54-67.

Priyanto, D. 2011. Strategi pengembangan ternak sapi dan kerbau dalam mendukung PSDS tahun 2014. Jurnal Penelitian dan Pengembangan Pertanian, 30(3): 108-116.

Rahmawaty, S dan D.A. Budianto. 2011. Peluang usaha penggemukan sapi dalam kandang kelompok di desa Tobu, kabupaten Timor Tengah Selatan, Nusa Tenggara Timur. J Ternak Tropika 12(2): 52-59.

Sukmayadi, K., A. Ismail dan A. Hidayat. 2016. Analisis pendapatan dan optimalisasi input peternak sapi potong rakyat binaan sarjana membangun desa wirausahawan pendamping (SMDWP) yang berkelanjutan di Kabupaten Tasikmalaya. Jurnal Ilmu Produksi dan Teknologi Hasil Peternakan, 4 (2):312-318.

Walia, S.S and N. Kaur. 2013. Integrated farming system-an 
Zootec Vol. 39 No. 2 : 266 -275 (Juli 2019) pISSN 0852-2626 eISSN 2615-8698

ecofriendly approach for sustainable agricultural environment-areview. Greener Journal of Agronomy Forestry and Horticulture. 1(1):001-011. 